\title{
A GESTÃO DA INFORMAÇÃO E DO CONHECIMENTO NAS ORGANIZAÇÕES: Condicionantes das Propriedades Gerais da Informação
}

\author{
Jailma Simone Gonçalves Leite \\ Mestranda em Ciência da Informação \\ Programa de Pós-Graduação em Ciência da Informação \\ Universidade Federal da Paraíba \\ jailmasimone@hotmail.com \\ Edivanio Duarte de Souza \\ Doutor em Ciência da Informação \\ Professor Adjunto do Curso de Biblioteconomia \\ Universidade Federal de Alagoas \\ edivanioduarte@gmail.com
}

\begin{abstract}
Resumo
Os estudos relativos à gestão da informação e do conhecimento concentram-se, em sua maioria, em técnicas de planejamento estratégico, vantagem competitiva e suas correlações. Faz-se necessário ampliar o debate e promover reflexões acerca das condições de gestão, considerando, preliminarmente, as propriedades gerais da informação. Trata-se de ampliar o debate sobre esta temática a partir do elemento humano e das práticas e dos processos que a envolve. Considera que as variáveis conceituais acerca do problema refletem os caminhos diversos que as organizações estão tomando na gestão do conhecimento.
\end{abstract}

Palavras-chave

Gestão da Informação. Gestão do Conhecimento. Propriedades Gerais da Informação.

\section{INTRODUÇÃO}

Embora não muito presente no campo da Ciência da Informação, as reflexões sobre as propriedades gerais da informação encontram espaço profícuo nos debates sobre as possibilidades de gestão da informação e do conhecimento. Autores divergem e outros convergem em reflexões sobre essas possiblidades, notadamente, nos espaços organizacionais.

Em geral, a gestão da informação e do conhecimento corresponde a um conjunto de estratégias que possibilita a identificação das necessidades de informação, a busca, o uso e o seu compartilhamento. Os estudos relativos a esse tema concentram-se, em sua maioria, em técnicas de planejamento estratégico, vantagem competitiva e suas diversas correlações. As discordâncias acerca dos conceitos, dentre outras questões, refletem os diversos caminhos que as organizações estão tomando na gestão da informação e do conhecimento. Enquanto uma linha enfatiza o suporte tecnológico como elemento propositivo e intrínseco aos novos modelos de gestão, outra defende o elemento humano como condicionante dos processos.

Com efeito, para Barreto (2003), "a produção ou geração de conhecimento ocorre em uma articulação, de passagem: uma função de transferência da informação. A assimilação da informação é a finalização de transferência, um estado de aceitação da informação". Por outro lado, Davenport (1998) aponta iniciativas tecnológicas como possibilidades de gerenciamento do conhecimento, ressaltando 
as formas de armazenamento, compartilhamento e utilização de informações.

Posteriormente, Davenport, Marchand e Dickson (2004) apresentam o processo cognitivo como condicionante para efetivar um modelo de gestão da informação, destacando a necessidade de uma gestão da atenção como condutor na busca pela qualidade, em contraponto à quantidade de informações no ambiente corporativo e fora dele. Ocorre que "a gestão da informação corresponde à parte do processo da gestão do conhecimento, por compreender que, embora esta se fundamente nas estruturas de informação, apresenta-se como um estágio qualitativamente superior" (SOUZA; DIAS; NASSIF, 2011, p. 57).

Parece, pois, pertinente desenvolver reflexões sobre as propriedades da informação como condicionantes desses processos gerenciais. Dessa forma, objetiva-se aprofundar os estudos relativos às possibilidades de transferência e utilização do conhecimento estratégico a partir da gestão da informação, à luz da Ciência da Informação.

A presente reflexão é parte de pesquisa de mestrado em desenvolvimento no Programa de Pós-graduação em Ciência da Informação da Universidade Federal da Paraíba (PPGCI/UFPB). Esta tem como fundamento a necessidade informacional de profissionais que atuam em diversos segmentos da sociedade, notadamente, nos sistemas de informação e comunicação. Para investigação do problema proposto foram realizados levantamentos bibliográficos e análises em torno dos conceitos e das perspectivas de gestão, procurando compreender as condições de gestão da informação e do conhecimento.

\section{INFORMAÇÃO E CONHECIMENTO: RELAÇÕES COMPLEMENTARIEDADES}

É consensual entre pesquisadores da área de Ciência da Informação que informação e conhecimento possuem um forte componente social, portanto, a produção, o acesso e o compartilhamento desses são condições significativas para $\mathrm{O}$ desenvolvimento sustentável e produtivo das corporações.

A produção ou geração do conhecimento é uma reconstrução das estruturas mentais do indivíduo através de sua competência cognitiva, ou seja, uma modificação em seu estoque mental de saber acumulado, resultante de uma interação com uma informação percebida e aceita. Esta modificação pode alterar o estado de conhecimento do indivíduo, ou porque aumenta o seu estoque de saber acumulado, ou porque o sedimenta, ou porque o reformula (BARRETO, 1999, p. 70).

Admite-se que informação é sempre um conceito complexo ao buscar esclarecimento em construtos teóricos, pois não é um fenômeno estático, está presente em todas as atividades humanas, inclusive na própria qualificação da sociedade contemporânea, que, entre outros, recebe o nome de sociedade da informação. No entanto, o uso da palavra isoladamente parece não possuir um significado expressivo.

As expressões "sociedade da
informação", "era da informação" e
"mundo da informação", são, hoje, de
uso corrente. Mas, é raro se encontrar
uma definição satisfatória para esta
palavra isolada; como nos casos do
amor e do ódio, é preciso anexar-lhe
algum qualificativo para revelar a sua
natureza concreta (LOPES, 1998, p.
22, grifo do autor).

Para Drucker (2002), informação é um conjunto de "dados dotados de relevância e propósito" e são as pessoas que conferem a estes atributos de relevância e propósito. Nesse mesmo horizonte, Barreto (1994) estabelece o "valor" da informação como elemento natural da formação da identidade individual, apontando sua especificidade para construção do conhecimento humano.

Como elemento organizador, a informação referencia o homem ao seu destino; mesmo antes de seu nascimento, através de sua identidade 
genética, e durante sua existência pela sua competência em elaborar a informação para estabelecer a sua odisseia individual no espaço e no tempo (BARRETO, 1994, p. 1).

A concepção de "valor da informação" para o conhecimento, como necessário à vida humana, é também adotada por Kobashi e Tálamo (2003, p. 9), ao asseverar que "a informação, como o alimento, provoca a fome, a carência de informação provoca a ausência de conhecimento". Nesse campo, a informação é tratada como um bem simbólico e não material. Essa é destacada por González de Gomez (1990, p. 117, grifo da autora) como uma "relação entre uma pragmática social da informação (ou 'meta-informação') e os 'mundos' de vida, de ação, de conhecimento, agindo na construção dos valores de informação".

Objetivamente Souza, Dias e Nassif (2011) destacam a necessidade de integração das estruturas de informação e de conhecimento, apontando as possibilidades de gestão dos elementos constituintes de inteligíveis coletivos em que esses são planejados, organizados e desenvolvidos.

A correlação entre gestão da informação e gestão do conhecimento, e, por conseguinte, a conjugação de seus estudos, parece ter por fundamento o entendimento de que as estruturas de informação disponíveis nos diversos suportes e recursos informacionais são também estruturas de conhecimento (SOUZA; DIAS; NASSIF, 2011, p. 60, grifo dos autores).

É também importante considerar a partir de Nonaka e Takeuchi (1997) que o conhecimento tácito corresponde àquele pessoal e específico ao contexto, difícil de ser formulado e comunicado. O conhecimento explícito ou "codificado" refere-se ao conhecimento transmissível na linguagem formal e sistemática. Dentro deste contexto, a externalização é um processo de articulação do conhecimento tácito em conceitos explícitos. $\mathrm{Da}$ combinação e categorização de conhecimento explícito, como realizado em banco de dados de computadores, pode gerar novos conhecimentos.

\section{GESTÃO DA INFORMAÇÃO E DO CONHECIMENTO: CONCEITOS E PERSPECTIVAS}

Preliminarmente, é importante considerar que se vivencia a uma sobrecarga de informação. Em contrapartida, estudos constatam que o processamento dessas informações declina consideravelmente. A natureza imensurável do conhecimento talvez seja o grande desafio para gestão da informação e do conhecimento no âmbito das organizações. "A gestão do conhecimento deve ser concebida num espaço epistemológico amplo dedicado à compreensão da relação mente-mundo, onde se dá o processo de conhecer" (SOUZA; DIAS; NASSIF, 2011, p.57).

De acordo com Alvarenga Neto (2005), as definições de gestão de recursos informacionais ou, simplesmente, gestão da informação podem ser apresentadas a partir da sobreposição da perspectiva da tecnologia da informação e da perspectiva integrativa. Os modelos contemporâneos de gestão da informação e do conhecimento têm compreendido que este último é produzido no sujeito. Porém, parece haver também uma percepção do conhecimento como um processo linear, e não cíclico e interativo. Nesse aspecto, pode-se afirmar que, nos processos de gestão, a concepção de fator humano não dá margem à sua emancipação, mas consolida a reificação do homem.

Estabelecer teorias e métodos de gerenciamento da informação e do conhecimento não é tarefa simples, visto a necessidade de compreender as diversas peculiaridades das propriedades da informação que podem condicionar o gerenciamento desta, bem como do conhecimento. Mikhailov, Cherniy e Giliarevskii (1980, p.74) reconhecem a existência de, pelo menos, doze perspectivas de propriedades da informação que condicionam a apropriação e a transferência do conhecimento.

De todas as propriedades peculiares à informação selecionamos doze que, 
acreditamos, são essenciais, e as organizamos do mais geral para o mais específico. Estas propriedades incluem o seguinte: inseparabilidade da informação científica de seu suporte físico; não-aditividade, nãocomutatividade e não-associatividade da informação científica; presença do valor; natureza social; natureza. Semântica e linguística (lógica); independência da linguagem que é expressa no suporte material e a partir dele.

Talvez, por isso, se justifique as particularidades da informação enquanto objeto de estudo da ciência, levando em consideração o aspecto humano envolvido no processo de criação da informação e sua efetiva transferência para um ambiente público, fenômeno pouco estudado. Conforme Barreto (2002, p. 10), "a transferência tem uma conotação de passagem, deslocamento a transmutação se coloca como formação de nova espécie por meio de mutações, como uma reconstrução de estruturas significantes".

Nesse sentido, a gestão do conhecimento tem por base a gestão da informação, embora esses processos talvez não sejam efetivos em decorrência da escassez de estudos aprofundados nesse campo e, por conseguinte, do desenvolvimento de metodologias e técnicas adequadas. mercadológicos, evocam conceitos, teorias e práticas relacionadas à gestão da informação e do conhecimento. No entanto, a disparidade dos aspectos conceituais exigem reflexões que possam contribuir para uma maior compreensão da temática, sobretudo estudos específicos que contribuam com a compreensão das propriedades e particularidades da informação como constitutivos da produção de conhecimento.

O presente trabalho representa, enfim, o ingresso em um campo de pesquisa, visando a aprofundar os estudos, em decorrência da discordância de alguns críticos que levantam a tese de impossibilidade de gerenciamento da informação e do conhecimento. A proposta não é invalidar as possibilidades de gerir tais processos, mas estudar com profundidade as condições e propriedades da informação para, então, compreender a gestão da informação e do conhecimento em toda sua dinâmica.

Considera-se a informação como um bem simbólico e não material, reforçando a possibilidade de integração entre informação e conhecimento. Admite-se a complexidade da gestão desses ativos intangíveis que exige maior imersão no estudo das propriedades da informação, considerando o sujeito e os contextos organizacional e cultural em que este encontra inserido.

\title{
4 CONSIDERAÇÕES FINAIS
}

$\begin{array}{ccc}\text { No mundo contemporâneo } & \text { os } \\ \text { discursos acadêmicos, tais quais } & \text { os }\end{array}$

\section{THE MANAGEMENT OF INFORMATION AND KNOWLEDGE IN ORGANIZATIONS:}

\author{
General Properties of Determinants of Information
}

\begin{abstract}
Studies on the management of information and knowledge are concentrated mostly in technical strategic planning, competitive advantage and their correlations. It is necessary to broaden the debate and promote reflections on the management conditions, considering, preliminarily, the general properties of information. It is to broaden the debate on this issue from the human element and the practices and processes that involves. Considers the conceptual variables of the problem reflect the diverse ways in which organizations are taking in knowledge management.
\end{abstract}

Keywords

Information Management. Knowledge Management. Properties General Information. 
Artigo recebido em 20/01/2014 e aceito para publicação em 30/04/2014

\section{REFERÊNCIAS}

\section{ALVARENGA NETO, R.C.D. Gestão do conhecimento em organizações: proposta de mapeamento conceitual integrativo. Belo Horizonte: Saraiva, 2005.}

BARRETO, A. As aplicações da informação: estratégia de atuação. Data Grama Zero revista de Ciência da Informação, Rio de Janeiro, n.4, v.4. p.1-4, 01 ago. 2003.

Disponível em:

<http://www.dgz.org.br/ago03/Ind_com.ht m\#continuação >. Acesso em: 29 jul. 2013.

A condição da informação. São Paulo perspectiva, São Paulo, v.16, n.3, 2002.

A questão da informação. São Paulo em perspectiva, São Paulo, v. 8, n. 4, 23 jan. 1994.

. O rumor do conhecimento. São

Paulo em Perspectiva, São Paulo, v. 12, n. 4, p.69-77, 1999.

DAVENPORT, T. H. Ecologia da informação. 6._ed. São Paulo: Futura, 1998.

DAVENPORT, T. H.; MARCHAND, D. A.; DICKSON, T. Dominando a gestão da informação. Porto Alegre: Bookman, 2004.

\section{DRUCKER, P. F. A administração na}

Próxima Sociedade. São Paulo: Nobel, 2002.

GONZÁLEZ DE GÓMEZ, M. N. O objeto de estudo da Ciência da Informação:

paradoxos e desafios. Ciência da

Informação, Brasília, v. 19, n. 2, p. 117-122, jul./dez. 1990. Disponível em:

$<$ http://revista.ibict.br/ciinf/index.php/ciinf/ article/viewFile/1376/1001 >. Acesso em: 08 ago. 2013.
Para uma reflexão epistemológica

acerca da Ciência da Informação.

Perspectivas em Ciência da Informação, Belo Horizonte, v. 6, n. 1, p. 5-18, jan./jun. 2001. Disponível em:

$<$ http://portaldeperiodicos.eci.ufmg.br/index. $\mathrm{php} / \mathrm{pci} /$ article/view/433>. Acesso em: 09 ago. 2013.

KOBASHI, N. Y.; TÁLAMO, M. F. G. M. Informação: fenômeno e objeto de estudo da sociedade contemporânea. Transinformação, Campinas, v. 15, edição especial, p. 7-21, set./dez. 2003. Disponível em:

$<$ http://www.brapci.ufpr.br/documento.php? dd $0=0000007542 \& d d 1=34129>$. Acesso em: 09 ago. 2013.

\section{LOPES, L.C. A Gestão da Informação: as} organizações, os arquivos e a informática aplicada. Rio de Janeiro: Arquivo Público do Estado do Rio de Janeiro, 1998.

MIKHAILOV, A. I.; CHERNYI, A. I.; GILYAREVSK, R. S. Estrutura e principais propriedades da informação científica (a propósito do escopo da Informática. In:

GOMES, H. E. (org.). Ciência da

Informação ou Informática? Rio de Janeiro: Calunga, 1980. p. 70-89.

NONAKA, I.; TAKEUCHI, H. Criação de conhecimento na empresa: Como as empresas japonesas geram a dinâmica de inovação. Rio de Janeiro: Campus, 1997.

SOUZA, E. D.; DIAS, E. J. W.; NASSIF, M. E. A gestão da informação e do conhecimento na ciência da informação: perspectivas teóricas e práticas organizacionais. Informação e

Sociedade: estudos, João Pessoa, v. 21, n. 01, p.55-70, Jan./abr. 2011. 